\title{
Fraud in the 2018 Egyptian presidential election?
}

\author{
Neil Ketchley*
}

September 25, 2019

\begin{abstract}
This research note scrutinizes official vote counts from the 2018 Egyptian presidential election. Drawing on data for 13,807 polling stations published by the Egyptian Electoral Authority, it uses the Election Forensics Toolkit to estimate a series of digit and distribution tests. The results point to statistical anomalies in voter turnout for polling stations located in Egypt's major population centers. The findings align with journalistic accounts of very low turnout in those areas and demonstrate how tools from electoral forensics can be applied to the study of elections in the Middle East and North Africa.
\end{abstract}

Keywords - Election forensics; Electoral fraud; Authoritarianism; Egypt; El-Sisi

${ }^{*}$ Walter Mebane provided guidance on using the Electoral Forensics Toolkit and generously shared the code to estimate the finite mixture models. The brilliant team at Daftar al-Ahwal provided access to an unreleased version of the WikiThawra dataset. Steven Brooke, Thoraya El-Rayyes, Marc Lynch, and two anonymous reviewers gave useful feedback and suggestions on the text. Neil Ketchley (neil.ketchley@stv.uio.no) is Associate Professor of Political Science in the Department of Political Science, University of Oslo. 


\section{Introduction}

Between March 26-28, 2018, Egyptians were summoned to vote in the second presidential elections held since former field marshal Abdul Fatah El-Sisi toppled Islamist president Muhammad Mursi in a military coup in July 2013. In the run-up to the vote all credible opposition candidates dropped out of the race after several were arrested or threatened. Mousa Mustafa Mousa, a last-minute, pro-regime figure, was the only other candidate on the ballot. Election officials reported that 41 percent of eligible Egyptians voted in the election, with El-Sisi securing 97 percent of valid ballots. The turnout figures, which are comparable to levels of turnout seen during Egypt's energetic but short-lived democratic transition, were greeted with skepticism amid reports of widespread voter apathy (Bloomberg 2018) and empty polling stations (Associated Press 2018a; The Guardian 2018).

\section{Election forensics}

The vote counts for the 2018 presidential elections can be scrutinized using tools developed by political scientists working in the field of election forensics. Election forensics is based on the idea that vote counts have regular numerical properties, and that any manipulation leaves distinctive patterns that can be detected statistically. Scholars have used tests from electoral forensics to examine suspected electoral fraud in a number of autocratic contexts, including Afghanistan (Weidmann and Callen 2013), Iran (Mebane 2010; Roukema 2013), and Russia (Bader and van Ham 2015). To conduct my analysis, I employ the Election Forensics Toolkit 2.0 (n.d.) developed for USAID by Walter Mebane and his colleagues at the Universities of Michigan and Maryland. This prototype online toolkit allows the user to implement a battery of tests that compare either the average of a given digit, or the distribution of the vote, to the value that we would typically expect to see if an election is free and fair. ${ }^{1}$ Importantly, the results generated by the Election Forensics Toolkit ${ }^{1}$ See Hicken and Mebane (2017: pp.37-38) for a detailed explanation of how typical values are derived. 
include a measure of uncertainty - operationalized as 95 percent confidence intervals that show how different a given value is from what we would expect to see under the null hypothesis of no manipulation.

The tests implemented in the Election Forensics Toolkit require information on the number of valid and spoiled ballots, the number of votes for a given candidate, and the number of electors in a given area. These can often be downloaded from the websites of national electoral authorities. Polling station or ballot box returns are preferred. If available, the coordinates of individual polling stations can be used to estimate tests for spatial autocorrelation that reveal whether anomalies cluster in space.

The authors of the Election Forensics Toolkit caution that if anomalies are detected by any one test, this does not prove fraud. Tests to detect anomalies in either the digits (Mebane 2013) or the distributions (Mebane et al 2014) of vote counts are sensitive to voters behaving strategically, such as through tactical voting. As a result, strategic behaviour, or simple human error, can show up as manipulation. Given this risk of false positives, we should be mindful that these statistical tests can only ever be confirmatory. At a minimum, we need to see anomalies detected across several different tests to have reasonable grounds to suspect that fraud has occurred. Even then, a definitive judgement of fraud requires corroboration with qualitative evidence obtained from, for example, inperson election monitoring.

\section{Background}

The 25th January Revolution in 2011 seemed to presage a new democratic era in Egypt. Following the ousting of Husni Mubarak, Egyptians participated in a series of competitive national elections, which produced a new constitution, a short-lived parliament, and the country's first democratically elected civilian president. While the results of these elections proved to be politically divisive, the competitive nature of these votes marked a profound departure from the electoral politics of the Mubarak-era, when the authorities 
used voter intimidation, ballot stuffing, and other frauds to produce outsized victories. ${ }^{2}$

Egypt's tentative democratic experiment was ended on July 3, 2013, when a military coup led by El-Sisi removed the Muslim Brotherhood's Muhammad Mursi from office. The military's takeover followed sustained protests that saw secular activists, fearful of an Islamist takeover and hoping to reignite a revolutionary process, mobilize alongside Mubarak-era regime figures and the country's security apparatus (see Ketchley 2017: ch.5). In the subsequent period, elections have emerged as a key tool for legitimizing El-Sisi's seizure of power. A constitutional referendum, which sought to strengthen the position of the presidency and the security establishment, was called in January 2014. This was followed by a presidential election held in May 2014. In the run-up to the vote, El-Sisi asked for turnout to exceed 80 percent (The Guardian 2014). In a bid to maximise participation, the regime scheduled a public holiday to coincide with the ballot and threatened non-voters with hefty fines. When Egyptians failed to turn out in large numbers - relayed in images of deserted polling stations (e.g. Buzzfeed News 2014) - the election authorities extended the vote for a third, unscheduled day.

Sisi was eventually installed as president with 96.9 percent of the vote; official turnout was 47 percent. To put these figures into perspective, Table 1 shows turnout percentages and the margin of victory for elections held in Egypt since 2011. Going by the official results, the 2014 presidential elections attracted greater popular participation than 3 out of 5 of the national votes held during the post-Mubarak democratic transition. ${ }^{3}$ This forms part of a broader pattern in which officially reported turnout in post-coup elections has tended to exceed, or closely track, turnout levels seen during Egypt's democratic transition. At the same time, the margin of victory has increased precipitously. This has formed the basis of two, inter-related narratives promoted by the El-Sisi regime: firstly, that the post-coup regime enjoys a popular mandate that equals or exceeds the ${ }^{2}$ On elections held under the Mubarak regime, see Kassem (2004) and Masoud (2014). ${ }^{3}$ The exception to this trend is the 2014 parliamentary election. This may reflect the regime's priorities: an enfeebled parliament with no popular mandate is less able to hold El-Sisi to account. 
Table 1: Turnout and margin of victory for elections in Egypt, 2011-2018.

\begin{tabular}{|c|c|c|c|c|}
\hline & Year & Election & $\begin{array}{c}\text { Voter } \\
\text { turnout }(\%)\end{array}$ & $\begin{array}{c}\text { Margin of } \\
\text { victory (\%) }\end{array}$ \\
\hline \multirow{5}{*}{ 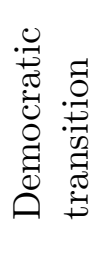 } & 2011 & Constitutional referendum & 41 & 55 \\
\hline & 2011 & Parliamentary elections (Lower house) & 54 & $\mathrm{~N} / \mathrm{A}$ \\
\hline & 2012 & Presidential elections (1st round) & 47 & 1 \\
\hline & 2012 & Presidential elections (2nd round) & 52 & 3 \\
\hline & 2012 & Constitutional referendum & 33 & 27 \\
\hline \multirow{4}{*}{$\begin{array}{l}0 \\
0 \\
0 \\
\frac{1}{0} \\
0 \\
0 \\
0\end{array}$} & 2014 & Constitutional referendum & 39 & 96 \\
\hline & 2014 & Presidential election & 47 & 93 \\
\hline & 2015 & Parliamentary elections & 28 & $\mathrm{~N} / \mathrm{A}$ \\
\hline & 2018 & Presidential election & 41 & 94 \\
\hline
\end{tabular}

Notes: Percentages have been rounded. Margin of victory is the difference in the share of the vote between the first and second place candidate. In the case of constitutional referendums, this is the difference between the share of the vote for the winning and losing option.

democratization process triggered by the 25th January Revolution; and secondly, that there is no popular alternative to El-Sisi's leadership.

As well as holding elections, the post-coup government has waged an unprecedented campaign of repression against Egypt's political opposition. To give an illustration: an updated version of the WikiThawra (forthcoming) dataset, sourced from court records, local news reports, and social media postings, contains records for over 125,000 political arrests in Egypt for the period from July 2013 to January 2018. Human rights groups have also documented the widespread use of torture, enforced disappearances, and extrajudicial killings (see Amnesty International 2019).

Repression intensified in the run-up to the 2018 presidential elections, when El-Sisi announced that he would stand for a second presidential term. Figure 1 is a daily time series of political arrests using the WikiThawra dataset for July 2017-July 2018. There is a detectable surge in arrests following the official commencement of the election campaign, which peaked on April 1, when 516 individuals were detained on a single day. Examining the period January 2017 to December 2018, negative binomial regression suggests that the daily arrest rate was 2.75 times higher $(95 \%$ CI $[1.37,5.55])$ during the 2018 election period. Among those arrested was the Islamist politician and former presidential candidate, Abdel Moneim Aboul Fotouh. Notably, the regime also detained Mubarak- 


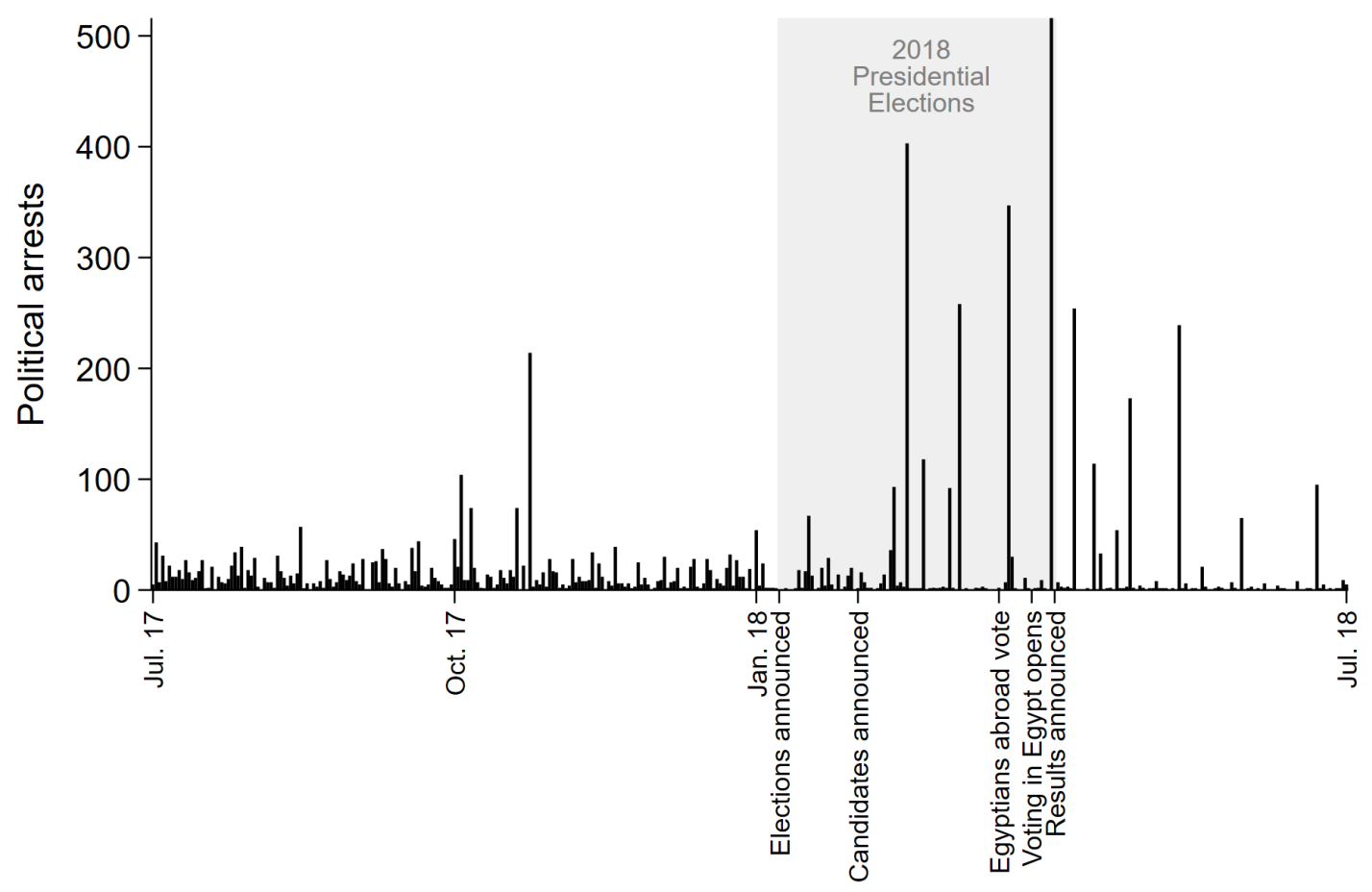

Figure 1: Daily rate of political arrests, July 2017 - July 2018. Notes: shaded gray area marks the 2018 presidential election period.

era figures who announced their intention to run, or else were forced to withdraw from the race under the threat of arrest. These included Sami Anan, a former general who played a leading role in the post-Mubarak transitional government (Mada Masr 2018). Ahmad Shafiq, Mubarak's last prime minister and the old regime candidate in the 2012 presidential elections, also withdrew his candidacy under pressure from the authorities (The Guardian 2017). In the face of this repression, all other candidates pulled out of the race. The ballot was only contested when Mousa Mustafa Mousa, a relatively unknown figure who had previously endorsed El-Sisi for a second term, belatedly announced that he would stand.

\section{Analysis of vote counts}

Disaggregated vote counts for the 2018 presidential election were published on the Egyptian Electoral Authority's website shortly after the results were announced (Egyptian 

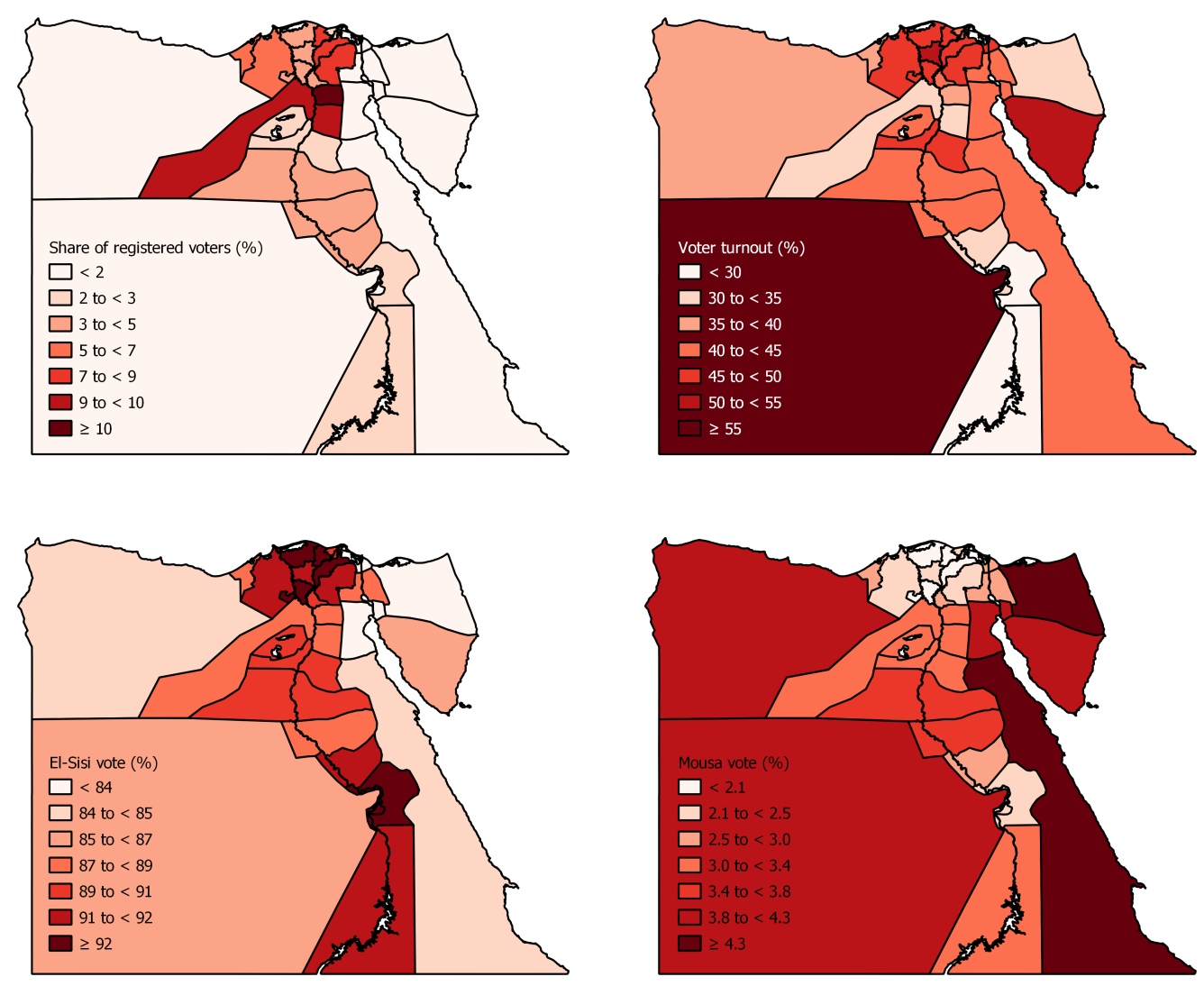

Figure 2: Clockwise from left: Share of registered voters in 2018; Voter turnout for 2018 presidential election; Percentage of valid votes cast for El-Sisi in 2018 presidential election; Percentage of valid votes cast for Mousa in 2018 presidential election.

National Election Authority 2018). ${ }^{4}$ This data includes the number of registered voters, voter turnout, and the number of votes for each candidate (see Figure 2). The number of votes cast by Egyptians located abroad was reported - but the number of registered Egyptian voters in a country was not specified, and so I confine attention to polling station returns from Egypt. Unfortunately, the precise locations of individual polling stations are often ambiguous, and so I do not implement tests that can account for spatial clustering in anomalous values. ${ }^{5}$

\footnotetext{
${ }^{4}$ At the time of writing, this information was recently removed from the website only to subsequently reappear. Regardless, the original page and corresponding Excel file can be recovered through the WayBack Machine (see the bibliography).

${ }^{5}$ This information could potentially be recovered by triangulating polling station names with the known location of polling stations used in previous elections.
} 

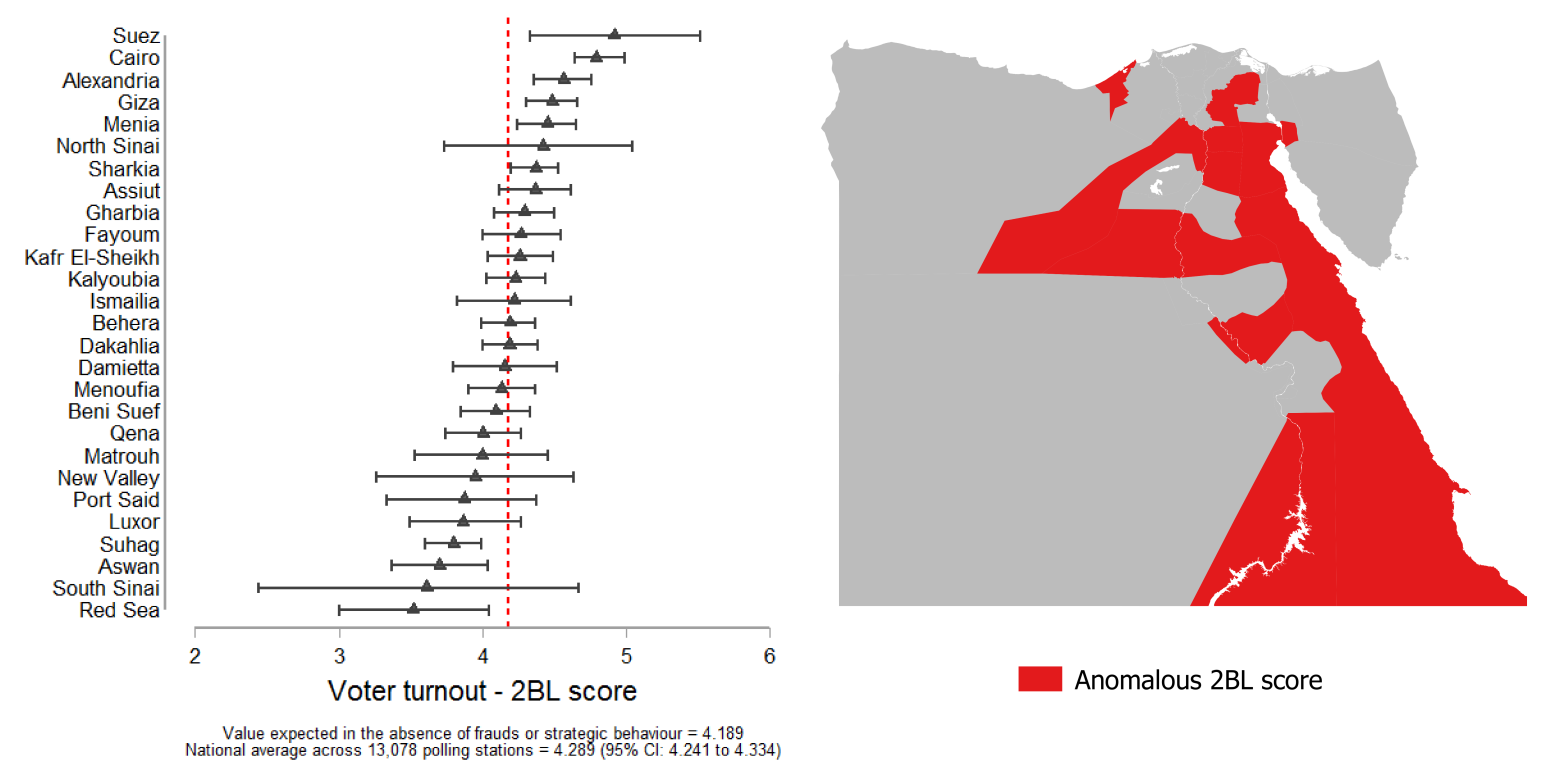

Figure 3: Second digit vote turnout scores by governorate located on 95 percent confidence intervals (left); Governorates with anomalous 2BL scores (right).

One test analyses the second digit of a vote count (i.e. if voter turnout in a polling station is reported as '2192', then ' 1 ' is the second digit). This test assumes that the second digit should follow a distribution similar to Benford's law, with each number from 0-9 more or less likely to appear as the result of a natural process. This numerical property is used in forensic accounting, to help auditors detect when figures have been fabricated (e.g. Durtschi, Hillison, and Pacini 2004).

For Egypt's recent presidential election, we can calculate the average of the second digit of turnout counts across the country's 13,087 polling stations and compare it to the typical value (known as $2 \mathrm{BL}$ ), which we would expect to find if no fraud was committed. In a clean election and in the absence of strategic behaviour, 2BL should be equal to 4.189. In the 2018 Egyptian presidential elections, the 2BL value is statistically significantly different from what we would expect to see in the absence of fraud or manipulation (Egypt 2018 2BL $=4.289,95 \%$ CI [4.241, 4.334]). Geographic disaggregation can help us to identify areas of the country where manipulation may have occurred. This is shown in the left-hand panel of Figure 3, with polling station returns grouped by governorate. The dashed line shows the typical value when fraud is absent. In nine governorates (marked in red on the map), second digit averages of official voter turnout figures significantly 


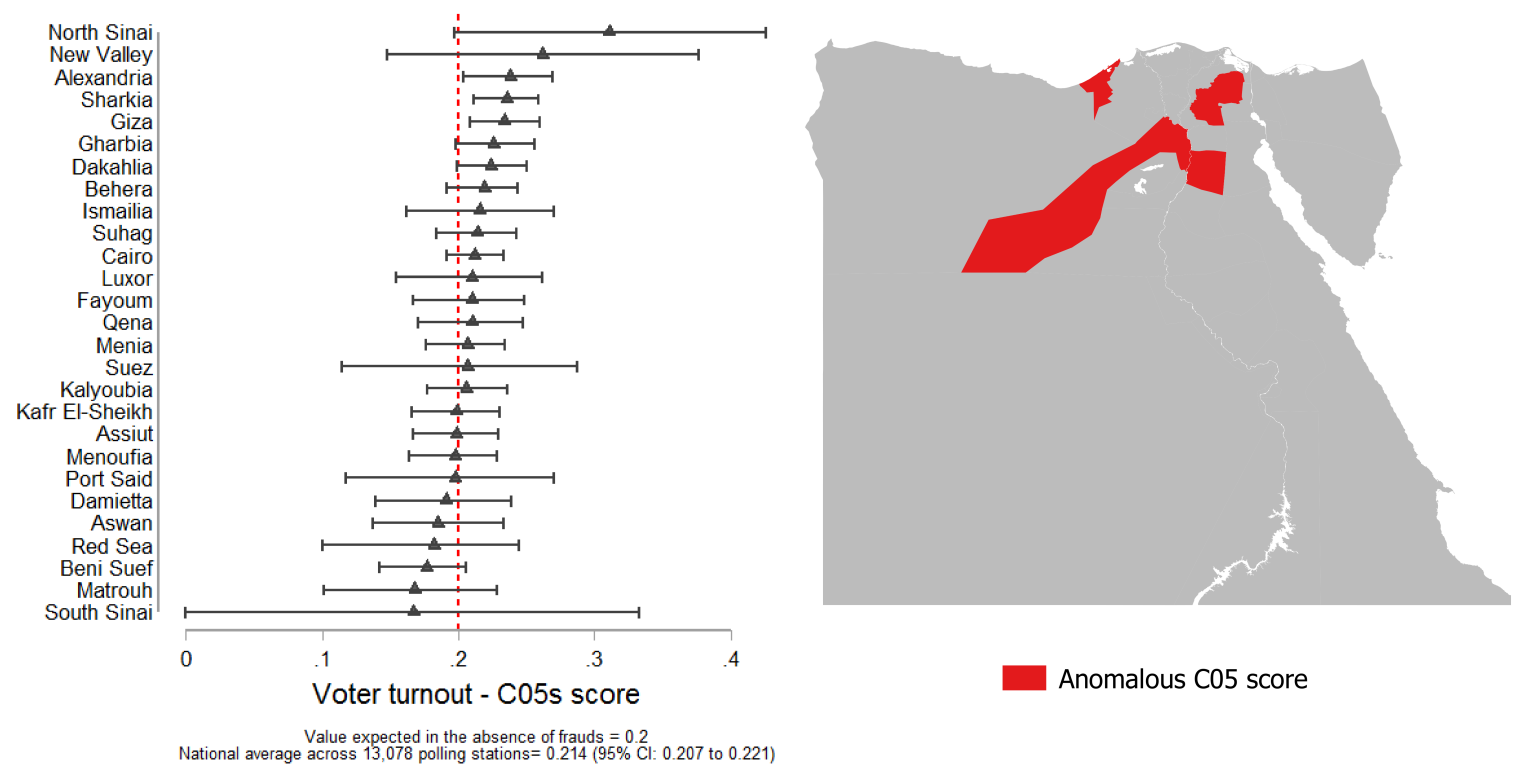

Figure 4: Final digit vote turnout scores by governorate located on 95 percent confidence intervals (left); Governorates with anomalous CO5s scores (right).

differ from what we would expect to find in the absence of fraud and strategic behaviour. Notably, anomalous second digits are found in turnout counts reported in the major population centres of Cairo, Giza, Alexandria, and Sharqia.

Another digit test that can indicate whether figures have been altered examines how often the last digit of a vote count is either 0 or 5 . We should expect that the last number of a vote count will follow a uniform distribution with the digits 0-9 being equally likely to be reported. The typical value expected in the absence of fraud (known as C05s) is 0.2. Again, in Egypt, the C05s score for official turnout counts is statistically different from the value that we would expect to find in an unproblematic election that was free of strategic behaviour (Egypt 2018 C05s $=0.214,95 \%$ CI [0.207, 0.221]). Closer examination reveals anomalous values in the final digit of turnout counts from Alexandria, Giza, and Sharqia (see Figure 4).

There are also statistical irregularities in the reported vote counts for Sisi's opponent. Research on electoral forensics suggests that rounded percentages of a vote (P05s) are sometimes deliberately manipulated by state agents to signal to higher authorities that fraud has occurred. This type of manipulation has been documented in Russia (see Kalinin and Mebane 2015). As Figure 5 reveals, Mousa Mustafa Mousa's vote share 


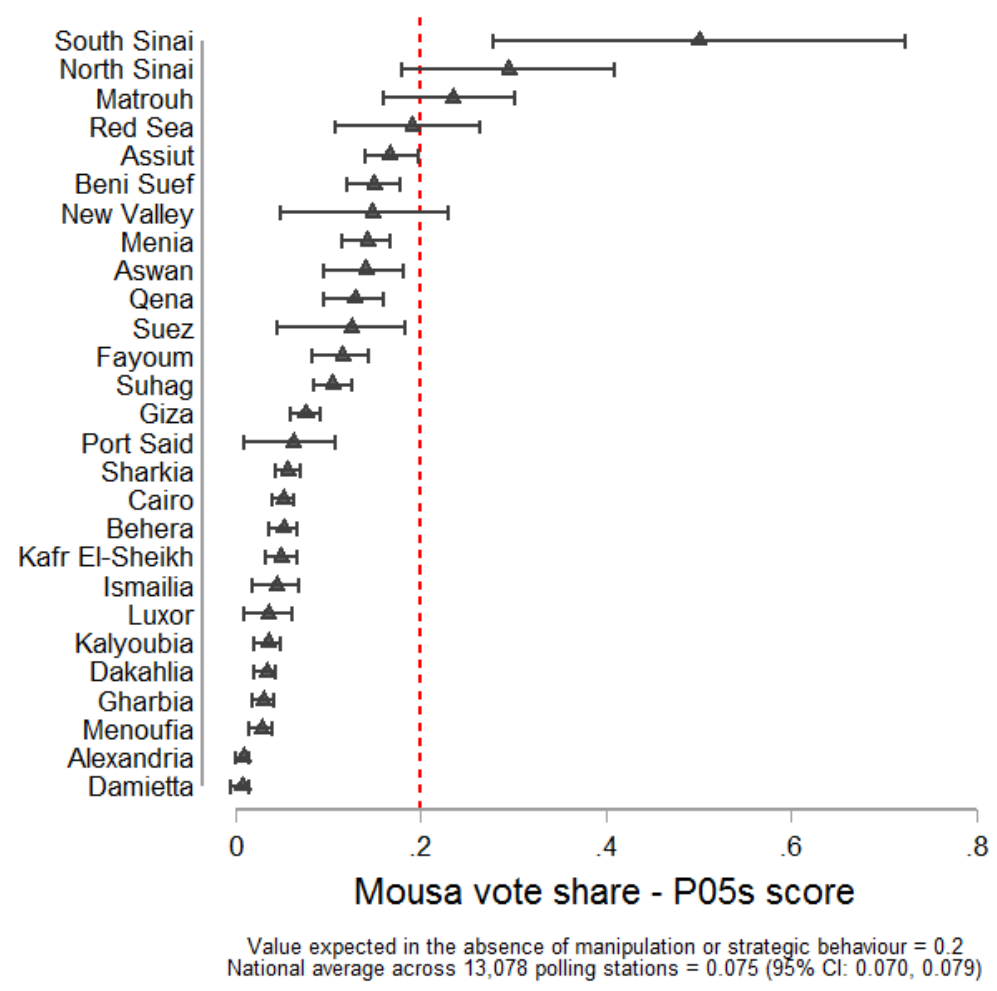

Figure 5: Rounded percentages for Mousa vote by governorate located on 95 percent confidence intervals.

appears to have been manipulated in polling stations located in nearly every governorate in Egypt.

The tests carried out so far have detected anomalies in the digits of official turnout and candidate vote counts. We can also look for evidence of a specific kind of fraud: mass ballot stuffing. Klimek et al (2012) argue that free elections have a fingerprint in which the percentage of voter turnout and vote share for the winner cluster around a mid-point. However, when very large numbers of votes are invented or stolen, some polling stations will report abnormally high levels of turnout where nearly all the votes go to one party or candidate, resulting in a bimodal or multimodal distribution.

Figure 6 is a two-dimensional histogram of Egypt's election fingerprint for the 2018 presidential election. There is some limited activity in the far top right hand corner of the histogram. This is due to polling stations reporting greater than 80 percent turnout where nearly all registered voters cast a ballot for El-Sisi. Probing these results further, estimates from a finite mixture model developed by Mebane (2016) suggest that some of El-Sisi's votes were invented from non-voters, and some were reallocated from Mousa to 


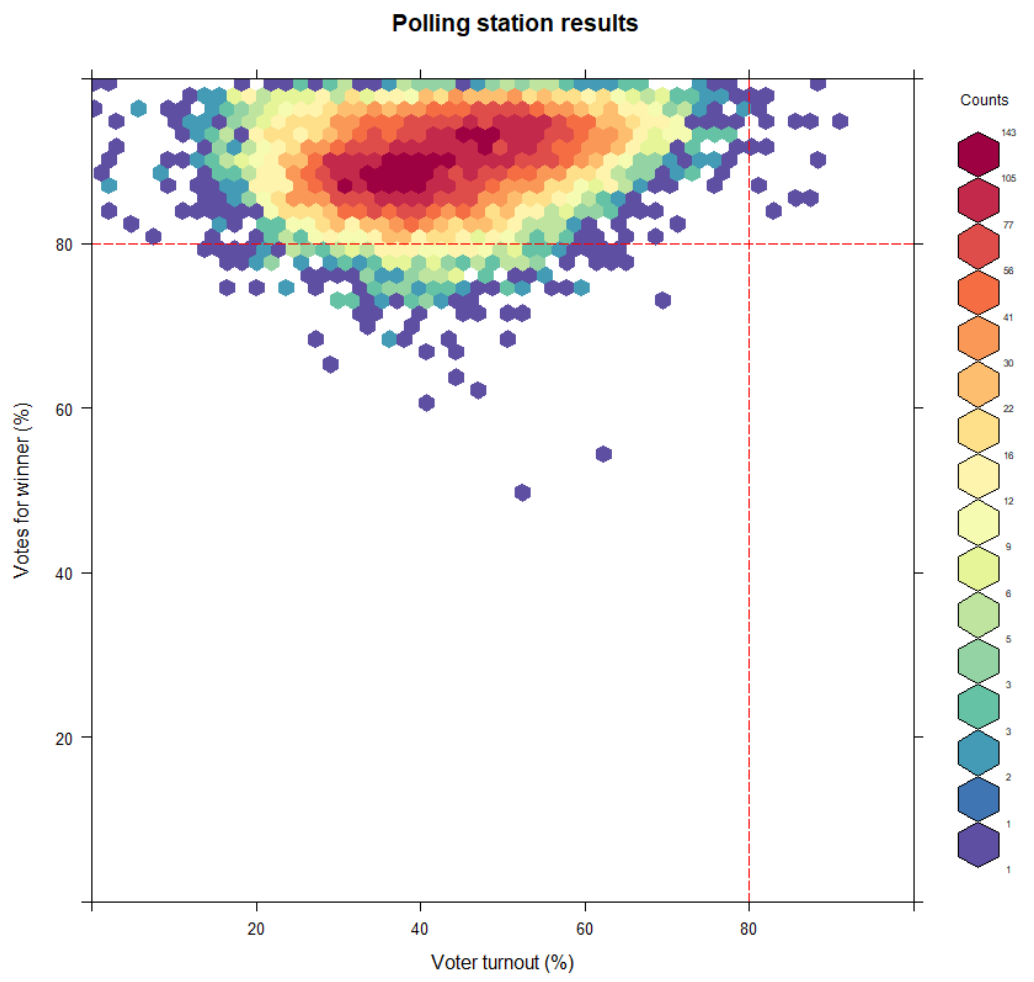

Figure 6: Polling station returns by voter turnout and votes for the winner.
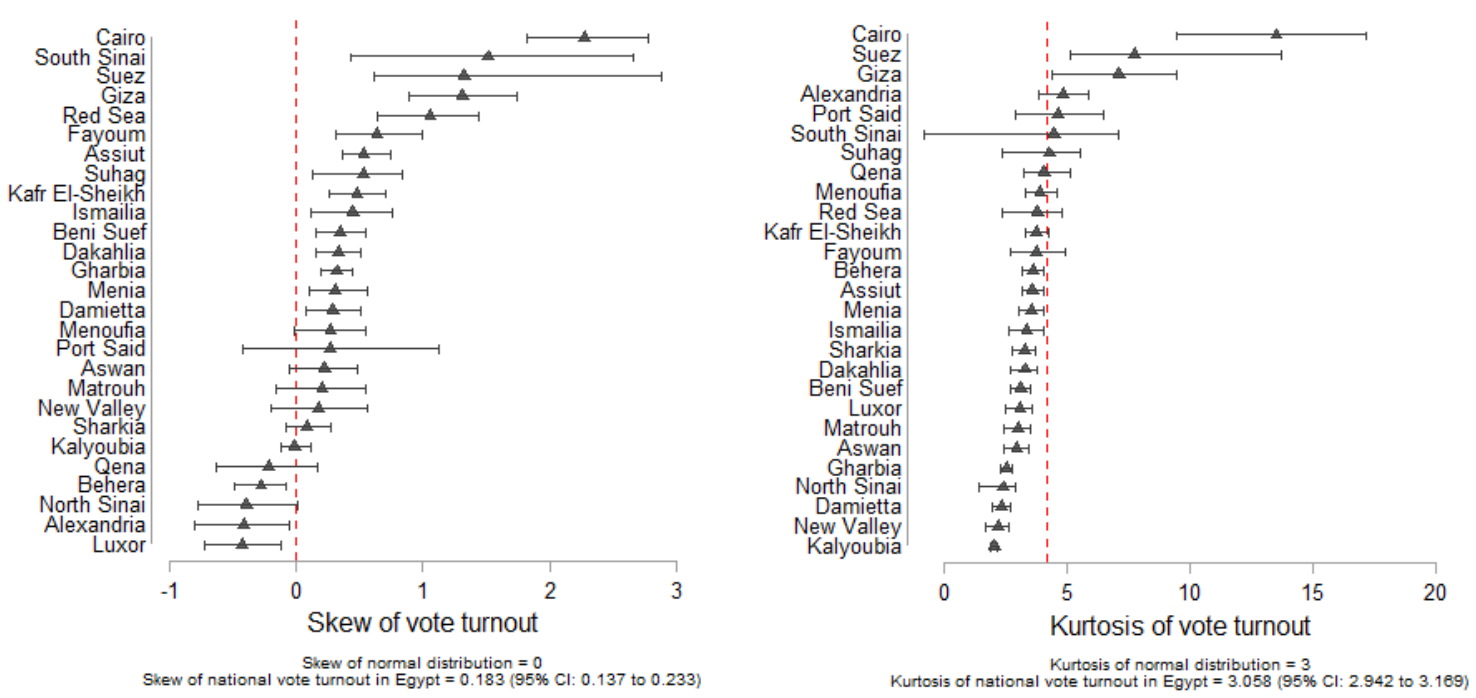

Figure 7: Skew and kurtosis of voter turnout by governorate located on 95 percent confidence intervals.

El-Sisi. However, the estimated extent of this fraud is small (less than 1 percent of votes reported), suggesting that ballot stuffing of a type and scale seen in other contexts was not a significant factor in the 2018 election.

A final distribution test compares voter turnout figures to vote patterns seen in fair elections. In an unproblematic election, voter turnout should approximate a normal 
distribution. However, two different measures shown in Figure 7 indicate that turnout figures for the 2018 Egyptian presidential elections follow non-normal distributions at both the national and the governorate levels.

\section{Conclusions}

To summarize, empirical tests developed by political scientists working in the field of election forensics reveal statistical anomalies in officially reported turnout and candidate counts for the 2018 Egyptian presidential elections. These anomalies are consistent with officials manipulating vote counts after the fact. Importantly, the anomalous turnout counts for Egypt's major population centers align with journalistic accounts of very low levels of voter participation in those areas (see e.g. Associated Press 2018b; Reuters 2018). A qualitative comparison with the elections held during the post-Mubarak transition is also helpful here. Those of us who were in Egypt for those elections will recall what happens when more than 40 percent of the adult population turns out to vote: the country's crumbling infrastructure is overwhelmed as voters queue outside of polling stations, public services are rendered unavailable, and large swathes of social and economic life are temporarily brought to a standstill. That we did not see similar scenes during the 2018 presidential elections (or indeed the 2014 presidential election, which claimed an even higher level of voter participation) renders official turnout figures even less plausible. Of course, it is important to reiterate that none of this constitutes definitive proof of fraud. At the same time, it bears remembering that there is no evidence of coordinated tactical voting for one candidate or the other. This would seem to rule out one form of strategic behavior that might produce the statistical anomalies described above. It is possible that other frauds, such as reported vote buying (see e.g. New York Times 2018), contributed to these anomalies.

Interestingly, the electoral fingerprint for the 2018 elections and the results from the finite mixture models point to only very limited evidence of mass ballot stuffing. This is not necessarily surprising. Recall that the 2018 presidential election was effectively a 
plebiscite for the El-Sisi regime with a relatively unknown pro-regime opposition candidate providing only token competition. With victory all but guaranteed, the regime's priority was to ensure that the election achieved a respectable level of turnout that would provide a mandate for El-Sisi's rule. In post-coup Egypt, what qualifies as a mandate is ostensibly benchmarked to turnout levels recorded in genuinely competitive elections held during the post-Mubarak transition. According to this logic, only around 40 percent of registered voters need to participate for an election to be hailed as legitimate. Parenthetically, this holds out implications for tests that look for ballot stuffing by identifying polling stations that report very high turnout percentages. In a context like post-coup Egypt, such values are unlikely to be present even if ballot stuffing does occur.

What lessons do these findings hold for how we understand the role played by elections in post-coup Egypt more broadly? Firstly, it is striking that El-Sisi's military-backed regime continues to engage in the facade of electoral politics. That it does so underlines the importance of elections, and in particular voter turnout, in providing El-Sisi with a veneer of democratic legitimacy. Here, Egypt conforms to a broader pattern in which post-coup regimes increasingly hold elections in a bid to justify their right to rule (see Grewal and Kurshi 2019). Secondly, if turnout figures have indeed been manipulated, this suggests that the post-coup regime struggles to motivate ordinary Egyptians to go out and express their support for it, even in the presence of strong inducements. This would seem to evidence a widely-held suspicion: that the El-Sisi regime is not nearly as popular as it purports to be.

Finally, as the WikiThawra data described above shows, we cannot divorce our understanding of electoral fraud in post-coup Egypt from the repressive context in which these elections are being staged. Regime opponents who seek to contest national elections face either imprisonment or exile. In this, any manipulation of vote counts should be understood as belonging to a broader repertoire of electoral authoritarianism that both reflects and reproduces the absence of meaningful democratic consultation in Egypt following the 2013 military seizure of power. 


\section{References}

Amnesty International. 2019. "Egypt: Gross Human Rights Violations under President Al-Sisi." Available at: https://www.amnesty.org/en/documents/mde12/0253/ 2019/en/ (last accessed August 12, 2019).

Associated Press. 2018a. "Egypt begins voting for president, with El-Sissi assured win," 27 March. Available at: https: //apnews .com/a59c23f48179468484405c78b0af7dac (last accessed August 12, 2019).

Associated Press. 2018b. "Egypt votes on final day, with all eyes on turnout," 28 March. Available at: https://apimagesblog.com/blog/2018/3/28/egypt-voteson-final-day-with-all-eyes-on-turnout (last accessed August 12, 2019).

Bader, Max and Carolien van Ham. 2015. "What explains regional variation in election fraud? Evidence from Russia: a research note," Post-Soviet Affairs, Vol. 31, No. 6, pp. $514-528$

Bloomberg. 2018. "Go Forth and Vote, Egyptians Told, as Apathy Fears Stalk Ballot," March 25. Available at: https://www.bloomberg.com/news/articles/2018-0325/-don-t-break-his-back-el-sisi-ponders-how-hard-to-push-egypt (last accessed April 28, 2019).

Buzzfeed. 2014. "Egyptians Snap Photos of Empty Poll Booths," May 27. Available at: https://www . buzzfeednews. com/article/sheerafrenkel/egyptians-snap-photosof-empty-poll-booths (last accessed August 30, 2019).

Durtschi, Cindy, William Hillison and Carl Pacini. 2004. "The Effective Use of Benford's Law to Assist in Detecting Fraud," Journal of Forensic Accounting, Vol. 5, pp: 17-34.

Egyptian National Electoral Authority. 2018. "Results" Available at: https://web. archive.org/web/20190126101613/https://pres2018. elections.eg/results-2018 (last accessed April 28, 2019).

Election Forensics Toolkit 2.0. (n.d.). Available at: http://electionforensics.ddns . net:3838/EFT_USAID/ (last accessed April 28, 2019).

Grewal, Sharan and Yasser Kureshi. 2019. "How to Sell a Coup: Elections as Coup Legitimation," Journal of Conflict Resolution, Vol. 63, No. 4, pp: 1001-1031. 
Hicken, Allen and Walter R. Mebane, Jr. 2017. "A Guide to Election Forensics," USAID Research and Innovation Grants Working Papers Series. Available at: https://pdf . usaid.gov/pdf_docs/PA00MXR7.pdf (last accessed April 28, 2019).

Kalinin, Kirill and Walter R. Mebane, Jr. 2012. "Understanding Electoral Frauds Through Evolution of Russian Federalism: The Emergence of 'Signaling Loyalty'," Available at SSRN: https://ssrn. com/abstract=1668154.

Ketchley, Neil. 2017. emphEgypt in a Time of Revolution: Contentious Politics and the Arab Spring, Cambridge: Cambridge University Press.

Klimek, Peter, Yuri Yegorov, Rudolf Hanel, and Stefan Thurner. 2012. "Statistical Detection of Election Irregularities," Proceedings of the National Academy of Sciences, No, 109, Vol. 41, pp. 16469-16473.

Mada Masr. 2018. "Former Armed Forces Chief of Staff Arrested, Referred to Military Prosecution after Announcing Presidential Bid," January 23. Available at: https://madamasr.com/en/2018/01/23/news/u/former-armed-forces-chief-of-staff-arrestedreferred-to-military-prosecution-after-announcing-presidential-bid/ (last accessed August 30, 2019).

Mebane, Walter R., Jr. 2010. "Fraud in the 2009 Presidential Election in Iran?," Chance, Vol. 23, pp: 6-15.

Mebane, Walter R., Jr. 2013. "Election Forensics: The Meanings of Precinct Vote Counts' Second Digits," unpublished working paper. Available at: http://wwwpersonal. umich.edu/ wmebane/pm13.pdf (last accessed April 28, 2019).

Mebane, Walter R., Jr. 2013. "Election Forensics: Frauds Tests and Observationlevel Frauds Probabilities," unpublished working paper. Available at: http://wwwpersonal. umich.edu/ wmebane/mw16.pdf (last accessed April 28, 2019).

Mebane, Walter R., Jr., Naoki Egami, Joseph Klaver, and Jonathan Wall. 2014. "Positive Empirical Models of Election Fraud (that May Also Measure Voters' Strategic Behavior," unpublished working paper. Available at: https://scholar.princeton. edu/negami/node/30441 (last accessed April 28, 2019).

New York Times. 2018. "For as Little as $\$ 3$ a Vote, Egyptians Trudge to Election 
Stations," March 27. Available at: https://www.nytimes.com/2018/03/27/world/ middleeast/egypt-election-sisi.html (last accessed April 28, 2019).

Reuters. 2018. "Sisi on course for big election win, early estimates say," March 28. Available at: https://www.reuters.com/article/us-egypt-election/sisi-oncourse-for-big-election-win-early-estimates-say-idUSKBN1H41GT (last accessed August 30, 2019).

Roukema, Boudewijn F. 2013. "A first-digit anomaly in the 2009 Iranian presidential election," Journal of Applied Statistics, Vol. 41, No. 1, pp. 164-199.

The Guardian. 2017. "Egypt: Former PM Ahmed Shafik Denies he was 'Kidnapped' after Mystery Disappearance," December 4. Available at: https://www .theguardian. com/world/2017/dec/04/egypt-former-pm-ahmed-shafik-denies-he-was-kidnappedafter-mystery-disappearance (last accessed August 30, 2019).

The Guardian. 2018. "Egypt election: 'I'm not going to vote. I know the result - Sisi will win'," March 28. Available at: https://www.theguardian.com/world/2018/mar/ 28/egypt-election-low-turnout-im-not-going-to-vote-i-know-the-result-sisiwill-win (last accessed April 28, 2019).

Weidmann, Nils B. and Michael Callen. 2013. "Violence and Election Fraud: Evidence from Afghanistan," emphBritish Journal of Political Science, Vol. 43, No. 1, pp: 53-75.

WikiThawra. Forthcoming. "Database of arrests, prosecutions, and judgements, 20112018," Excel file. 